\title{
Lapurdum
}

LAPURDUM Euskal ikerketen aldizkaria | Revue d'études basques |

Revista de estudios vascos | Basque studies review

$11 \mid 2006$

Numéro XI

\section{Ziutateaz-eko hiria}

\section{Mikel Ayerbe}

URL : http://journals.openedition.org/lapurdum/223

DOI : 10.4000/lapurdum.223

ISSN : 1965-0655

Éditeur

IKER

Édition imprimée

Date de publication : 1 novembre 2006

Pagination : 49-57

ISBN : 978-2-86781-474-7

ISSN : $1273-3830$

\section{Référence électronique}

Mikel Ayerbe, « Ziutateaz-eko hiria », Lapurdum [Linean], 11 | 2006, Sarean emana----an 01 avril 2008, kontsultatu 19 avril 2019. URL : http://journals.openedition.org/lapurdum/223 ; DOI : 10.4000/ lapurdum.223 


\title{
Ziutateaz-eko hiria'
}

\author{
Mikel AYERBE \\ Literatur teoria eta literatura konparatuan eta Euskal Filologian lizentziatua.
}

\section{ZIUTATERA BIDEAN}

Ziutateak hamaika ikuspuntu ezberdinetatik jorratu izan dira literaturaren magalean; baina euskal literaturari dagokionez, Atxagaren Ziutateaz ${ }^{2}$ liburua ahalegin nabarmena da, gaia bera titulu bihurtu eta hiriaren irudi jakin bat eraikitzeko.

Ondorengo lanak Atxagak lantzen duen ziutatearen irudia aztertzea izango du xede nagusi eta honetarako, batetik, Ziutateaz liburuak aurkezten dituen ardatz tematikoak azalduko ditugu eta bestetik, liburuan biltzen diren keinu intertestualen bitartez eratuko dugu hiriaren inguruan egiten den gogoetaren hurbilpen bat.

Atxagaren lanean sartu aurretik, Walter Benjaminek hiriari buruz egiten dituen gogoetak azpimarratu behar dira. Idazle honen obrari buruzko Para Walter Benjamin (K. Scheeurmann, 1992) lanean, hiriaz ematen den ikuspuntua Jordi Llovet-ek "Walter Benjamin, el paseante en la ciudad: La obra de los pasajes" artikuluan ederki biltzen du. Walter Benjaminek hiriaz duen ikuspuntua Baudelaire eta bere garaikideek hiriaz zuten ikuspuntutik abiatzen da baina beste urrats bat ematen du; hiria, egunerokotasun astunaren eta kaosaren metafora horri errotik heldu eta itxuraz azalekoak diruditen hiriko gertakariak aztertzen hasiko da, hiria bilakatu den metropoli edo cosmopoliaren sustraietan egon daitezkeen ezkutuko arauak iradokitzeko. Garapenaz Walter Benjamin-ek zuen ikuspuntu ezkorra aldiz, aipu batek laburbilduko luke: "Ez dago kultur adierazpenik, bere borretan ankerkeriaren adierazpen ere ez denik" (K. Scheurmann, 1992: 227).

Atxagak Ziutateaz liburuan planteatzen duen hiriaren ikuspuntua giro honetan kokatu behar da; hiri krudel eta anker bat, non bizirauteko ankerki jokatu behar den, non ihes egitea bertan jarraitzeko modu bat besterik ez den. Atxagak bere hastapenetako lanean distopia bat aurkeztuko digu, utopiaren ukazioa islatzen duen ziutate bat, eta gai honek bere horretan garrantzia gehiago bereganatzen du

1 - Ikerlan honen jatorria 2004 urtean Euskal Filologia ikasketen barruan "Garaiko euskal literatura eta unibertsala" irakasgairako egin nuen lanean dago. Hemen argitara ematen dudana, ikerlan horren laburpen-moldaketa besterik ez da, Ziutateaz eleberriaren inguruko ikerlan luze eta sendoagoa burutzen baitiartut.

2 - Lan hau egiteko Ziutateaz liburuaren 2. argitalpena erabili da: Atxaga, Bernardo; Ziutateaz, Donostia, Erein, 1986. 
Atxagaren ibilbide literarioa jarraitu eta distopiatik utopiara egingo duen bidea aintzat hartzen badugu.

\section{ZIUTATEAZ}

$\rightarrow$ Sinopsi-azalpena: istorio baten inguruan pilatzen diren hainbat istoriok osatzen duten liburu hibridoa da Ziutateaz; narrazioak, poemak, antzerki lanak, irudi espresionistak etab. biltzen dira liburu honetan. Liburuaren 76ko lehenengo argitalpena ere bi tiralditan egin zen; liburu zatikatua beraz, hasiera hasieratik.

Argumentuari dagokionez, espiralean eraikitako istorioen erdigunean Ikaro errebeldeen aurkako borroka kokatu behar da; gai honen inguruan korapilatzen dira gainerako istorioak: Scardenalli borrero nagusiaren bidaia iniziatikoa eta boterea eskuratzeko egingo dituen ekintza makurrak; honen idazkari-lanak beteko dituen Antonin pertsonaiaren narrazioa; krimen krudelen biktimen istorioak...

Gai ilun eta gertaera zakar hauek guztiak, giro hits eta surrealista batean kokatzen ditu Atxagak, amets edo amesgaizto izan daitekeen itxura emanez, istorioak espazio eta denbora zehaztugabe batean ipiniz. Helburua argia da; gatazka eternalak edonon eta edonoiz jazo daitezkela adieraztea. Ziutateaz-eko kontrazaleko Atxagaren hitzak bilduz: "Iruditzen zitzaidan guk bizi genuena beste askok ere bizi izandakoa zela eta etorkizuneko jendea ere ez zela libratuko, bizi beharko zuela".

$\rightarrow$ Ardatz tematikoak: "Ziutateaz eta Etiopia: obsesio berdinez eraikitako bi unibertso" artikuluan, Josu Landak bi lan hauetan Atxagaren ardatz obsesiboak eta bi unibertsoen arteko berdintasunak eta desberdinatsunak jorratzen ditu.

Ardatz tematikoen artean, Ziutatearen gaia azpimarratu behar dugu, sorleku eta helmuga gisa. Izenburutik bertatik ziutateak sortzen dituen gatazkak agerian uzteko saioa egiten du Atxagak. Liburua deserrotze batetik abiatzen da, errari dabiltzan lau lagunen bat-egitetik, laberintoaren hasieran noraeza iradokitzen duen eszena batetik. Ziutatea helmuga eta irtenbide gisa planteatzen da baina hainbatetan esan izan den bezala, norberak bere barruan darama bakoitzaren ziutate propioa. Liburu hasierako pasarte bat parafraseatuz, antzua baita beste ziutateen esperantzan ihes egitea, ihes egitea bertan ezin jarraitzeak eragindakoa denean.

Honela, bestelako ardatz tematikoek hiriaren ikuspegiarekin zuzeneko lotura dute eta Josu Landak aipatzen dituen beste ildo tematikoek (apatriden gaiak, bidaiaren alegoriak, krudelkeriaren gorazarreak eta poetaren irudiaren desmitifikazioak) hiriaren inguruan harilkatzen den giro hits, hertsi eta ankerra zehazten eta ulertzen lagunduko dute. 
Ardatz tematiko hauen sustraietan erabateko itsusikeriaren estetika nagusituko den heinean, intertestualitatearen atalean jorratuko ditugun pertsonaiek ere erabateko garrantzia izango dute, hauek izango baitira aurkezten den hiri horretako biztanle eta protagonista.

\section{ZIUTATEKO BIZTANLEAK}

Liburuan agertzen diren pertsonaiak aztertzeko liburuan agertzen diren keinu intertestualak azaltzea ezinbesteko lana bilakatzen da. Honetarako, intertestualitate terminoa lehendabiziko aldiz erabili zuen Julia Kristeva-ren hitzetatik abiatu behar gara; "testu orok aipu-mosaiko bat osatzen du, testu orok beste testuen barneratzea eta eraldaketa eskaintzen du (..), bizkuntza poetikoaren irakurketa, gutxienez, bikoitza da" (Kristeva, 1978: 188).

Hitz hauek argi esaten duten bezala, intertestualitatea lan baten barnean aurkitzen diren beste lanen oihartzuna litzateke. Eta hau izango da bereziki Ziutateaz liburuan aztertuko duguna; beste idazle, obra, aipu, literatur korronte... nola agertzen zaizkigun Atxagaren liburuan, eta idazleak berak nola erabili dituen agerian edo ez hain agerian dauden erreferentzia literarioak.

Honela bada, batetik intertestualitate esplizitua eta bestetik inplizitua bereiziko ditugu. Intertestualitate esplizituaren atalean agerikoak edo ia nabarmenak diren erreferentzia literarioen azterketa egingo dugun bitartean, intertestualitate inplizituan irakurketa hain agerikoak ez diren eta muturreko irakurketa inplizitu batek eragindako interpretazioak landuko ditugu.

\section{$\rightarrow$ Intertestualitate esplizitua:}

-Paratestua testu literarioa inguratzen edo biltzen duen guztia litzateke, hasi izenburutik bertatik eta edizioak berak eman dezakeen informaziora arte. Ziutateaz-en paratestuari dagokionez, lehenik eta behin bigarren argitalpenaren azaleko irudia hartu behar da kontuan. Bertan Arnold Böcklin (1827-1901) pintorearen "Hildakoen irla" margolan esanguratsua agertzen da. Arnold Böcklin europar sinbolismoaren korrontearen barnean kokatu behar da eta aipagarria da pintore surrealistetan, bereziki Giorgio de Chirico-gan eta Max Ernst-engan, izan zuen eragina.

Lehenago esan bezala, Ziutateaz-en joera sinbolistek eta surrealistek oihartzun handia dute, baina margolan honen kasuan, lotura are eta estuagoa dela esan behar da. Batetik, "Hildakoen irla" kuadroan uharte batera iristen ari den txalupa bat eta Caronte pertsonaia mitologikoa ageri dira, itzulerarik ez duen arima bat irlara gidatuz. Baina bestetik, fikzioan bertan Atxagak "Hildakoen irla" propio bat berreraikitzeko aitzakia da eta horretarako fikzioko pertsonaiak margolaneko eszenan txertatuko ditu. 
"(..) uharte bat da, bi harkaitz izugarri eta berdeskaz osatua.

Erdialdean zuhaitz batzuk ere badaude, luma itxurakoak, harkaitzak baino

gorago igotzen direnak. Harkaitz paretetan zuloak daude, zauriak dirudite.

-Non gaude, Hyronimus?

-Bidaiaren azkenean, Ikaro-en uhartean." (Atxaga, 1986: 37)

Ondoren, joku intertestuala borobilduz, Ziutateaz-en berreraikitako uharte hori Arnold Böcklin-en "Hildakoen irla" dela baieztatuko da; "Ez dago dudarik. Ikaroen uhartea bilotzen uhartea da" (Atxaga, 1986: 38).

Bestalde, testu literarioan barneratu aurretik eta lehen aipaturiko kontrazaleko Atxagaren beraren hitzak eta J. M. Iturralderen hitzaurreaz gain, idazleak hiru eskaintza eta aipu bat egiten ditu bigarren argitalpenean.

Hiru eskeintzei dagokienez, esan behar da ilunak bezain esanguratsuak direla. Bata idazketaren inguruan gazteleraz idatzitako poema gordina da; bigarren poemak familia du hizpide eta hirugarrena berriz lagun zaharrei eginiko keinua litzateke. Azken hau oso modu ilunean egina dago, izenak aipatzen badira ere mozorrotze ahalegin bat atzeman baitaiteke. Honen adibide da "Cesar petit kamikaze" bezala aurkezten den izenaren atzean ezkutatzen dena, Cesar hau bera izango baita Soinujolearen semea-n agertuko den Cesar irakaslea ${ }^{3}$, David pertsonaiarekin gaztaroan harreman berezi bat izango duena eta azkenean politika kontuengatik mehatxatuta amaituko duena.

Hiru eskaintzen ondoren Ezra Pound-en elkarrizketa zati bat gehitzen da. Hitzak ez dira inolaz ere inozenteak eta badute ondoren etorriko den guztiarekin loturarik. Elkarrizkeko azken erantzuna irakurtzea besterik ez dago Ziutateaz-en irakurketa girotzeko: "Bizitzara ez nau ezerk lotzen. Hitz batean esanda, lur jota nago" (Atxaga, 1986: 15).

-Intertestualitate esplizituaren atalean aztertu behar dira orobat, egileak erabiltzen dituen pertsonaien izen sinbolikoak. Izen sinbolikoen artean hiru azpiatal bereizi daitezke:

1.- Iturri klasikoko izenak: Atxagak iturri klasikoko Ikaroren mitoa berreskuratzen du bere liburuko errebeldeak izendatzeko. Loturak egitea ez da zaila; Ikarok argizarizko hegoekin hegan egin nahi izan zuen gisa berean, Ziutateaz-eko Ikaroek ere hegan egin nahi izango dute bizi duten zoritxarreko egoeratik alde egiteko. Baina Ikaroren mitoan bezalatsu, ziutateko arauek ezin dela hegan egin zehazten dute eta ahalegin honengatik Ziutateaz-eko Ikaroek ere gorriak ikusi beharko dituzte.

3 - Autoreak berak erraztutako informazioa. 
Hyeronimus-ek aldiz ez darama mitologiako izenik, baina izana iturri klasikoari zor dio, Caronte-ren moldaketa baita liburuan agertzen den Ikaroen buruzagia. Hyeronimus eta Caronteren ezaugarriak antzekoak dira, ezaugarriak berez ezohikoak izanik ere biak baitira txalupa-zain itsuak. Bestalde, iturri klasikoko Carontek txanpon bat eskatzen bazuen Estigia ibaia igarotzeko, Ziutateaz-eko Hyeronimusek hirira eramateko ere pasahitz bat behar da. Eta pasahitz hauxe izango da Ikaroen irudia esplizituki gogora ekartzen duen beste pasartea:

"-Gure ziutatera joan nabi baduk, har ezak ibai grisaren bidea, bertan dagoen kai ttikia bilatuz. Han txalupa bat egongo duk, eta txalupari itsu bat, Hyeronimus... (...). Hik esan egiok; nire bibotza zilarrezkoa da eta argizarizkoak ene hego ederrak. Nabikoa izango duk, berak konprenituko dik" (Atxaga, 1986: 32).

2.- Euskal tradizioko izenak: herri tradizioa aintzat hartuta Bilintx eta Loiola izenak aipatu behar dira. Loiola, Loiolako Inazio ezagunari ezinbesteko aipamen bat eginez, ziutateko botere espiritualaren eredu izango da. Scardenallik ordea, gupidagabe bere heriotza tramitatuko du ikuskizun baten bitartez. Ikuskizun honek "Bilintxi omenaldia" izenburua darama eta antzerki bat izango balitz bezala, oholtza gainean bertan hilko dute Loiola, Bilintxen pertsonaia interpretatzen ari den bitartean.

Honela bada, kontuan hartu behar da bi pertsonaia entzutetsu hauek oso bestelako trataera dutela Ziutateaz liburuan. Batetik, botere espiritualarekin bukatzen du liburuko pertsonaiak eta bestetik, Bilintx bertsolaria barregarri (edo negargarri) izaterainoko antzerki baten erdian kokatuko da, bere bizitza tristearen errepaso krudel baten ikusle. Antzerkiko koruak ez dio Bilintxen bertso ezagunenetakoa behin eta berriz errepikatzeari utziko: "triste bizi naiz eta hilko banintz bobe".

3.-Bestelako izen sinbolikoak: pertsonaia nagusien artean ere egileak teknika berdina erabiltzen duela antzeman dezakegu; Scardenalli, Antonin eta Theo izenen kasuan bereziki.

Scardenalliri dagokionez, Hölderlin (1770-1843) poeta ospetsua aipatzea ezinbesteko bilakatzen da. Alemaniako poeta esanguratsu hau erotu egin zen eta erotu ondorengo poemak Scardanelli izenez izenpetzen zituen. Aitzakia hau erabiliko du Atxagak bere pertsonaia nagusia izendatzeko, eta aitzakia hau erabili daiteke liburuko Scardenalliren ezaugarriak ulertzeko ere.

Antonin pertsonaia dela eta, Antonin Artaud (1896-1948) artistarekin aurkezten dituen antzekotasunak ere nahiko esplizituak dira. Antonin Artaud-ek XX. mendeko antzerkigintza eraldatu nahi izan zuen "Ankerkeriaren antzerkia" deitutako antzerki molde bat landuz. Ankerkeriaren antzerki honen teorizazio laburra Artaud beraren Le théâtre et son double (1938) antzerkiari buruzko saiakeran irakur daiteke. Teatro 
molde honek antzerki psikologikoa baztertu eta antzerki fisiko bat du helburu, non garrasien eta oihuen ankerkeriak eta krudeltasunak helburu objektiboa izango duten, non ongia desira baizik ez den izango eta gaiztakeria berriz errealitate gordin.

Ziutateaz-eko Antonin pertsonaiak ere, Scardenalliren idazkari-bufoi bihurtu aurretik komediante iragana zuen. Honela dio liburuko pasarte batean; "hona etorri arte soldata txiro batekin bizi nintzen, ziutatean zegoen bi txanponetako teatro ttiki batean lan eginez, sortzez izan dudan komeriante kutsuz baliaturik" (Atxaga, 1986: 60).

Ez da kasualitatea bi Antoninen arteko lotura, eta harreman hau hertsiago ulertzen da Scardenallik Loiola paretik kentzeko prestatzen duen antzerkia aintzat hartzen badugu. Antzerki hau Ankerkeriaren antzerkiaren oinordeko baita, liburuan bertan esaten den bezala, ziutatearen espiritua panis et circus esanaren arabera moldatu nahi baitu Scardenallik. Lehen aipaturiko antzerki lanaz ari delarik, Scardenallik honakoa dio: "nola Loiola hiltzeko -panis- teatro bat idatzi dudan, jendearen entretenigarri biburtuko da-circus- panis-aren defentsa bori" (Atxaga, 1986: 68).

Egia esan, Scardenallik izatez Antoninen papera betetzen du antzerkia berak idazten duen neurrian, baina gertakari hau ere zaindu egiten du egileak irakurleari beste keinu bat eskainiz. Honela, Scardenalli eta Antonin antzeztuko duten antzerkiaz ari direnean, Antoninek bere zalantzak adierazten dizkio bere nagusiari eta honen erantzunak ez du zalantzarako lekurik uzten; "Antonin,... oso zahartua gelditu baiz teatro kontuetan" (Atxaga, 1986: 70).

Theo pertsonaia aldiz, ilunagoa da. Vincent Van Gogh-en anaiari egiten dio erreferentzia baina bien arteko lotura lausoagoa da. Theo pertsonaiaren berri gehienbat bere poemen bidez lortzen dugu, eta poema hauek duten tonu hits eta ilunak ez du erabateko lotura egitea errazten. Hala ere, poema batean aipamen esplizituak bilatzen ditugu Van Gogh eta anaitasunari buruz. Poema honetan bigarren pertsona nagusitzen da eta norbaiti zuzentze honetan egileak kontuan hartzeko datuak barreiatzen ditu poeman zehar.

Batetik, Van Gogh-i egiten zaion aipamena aurkitzen dugu poemaren azkenengo lerroetan. Hain zuzen:

"Eta, ordurako,

ezkutatuak izango dituk Van Gogh,

edo bi,

bi herorri,

mintzen binduten bele multzokada gosetiak" (Atxaga, 1986: 24). 
Poema zati honetan, Van Gogh-i egiten zaion aipamen esplizituaz gain, pintore honen bizitzako azken lanari ere aipamen zehatza egiten zaio, bele talde bat izan baitzen Van Gogh-ek marraztu zuen azkenengo koadroa. Irudi hau berriro agertuko da Theoren beste poema batean, bere heriotza gerturatzen ikusiko balu bezala, honela baitio; "Niregana ere heldu zara hegal luzeetako txori iluna" (Atxaga, 1986: 119).

Van Gogh-en anaiaren irudiarekin lotu dugu Theo, eta honetarako arrazoiak aurreko poema horretan bertan aurkitu behar dira. Bertan "Ez, (MAINAIA)" bertsoa agertzen da eta "mainaia" horretatik eratortzen den hitz nabarmenena anaia da. Irakurketa arriskutsu bat izan daiteke, baina era berean, aztertutako datuetatik eratorri daitekeen interpretazio bat ere bada.

Bestelako aipamen bat merezi du Caryl Chessman-i egiten zaion aipuak. Narrazioaren une batean, Scardenalli pertsonaiak sinatzen duen poema bat ematen da aditzera eta bertan Caryl Chessman-en heriotza izango da hizpide.

Caryl Chessman (1921-1960), poeman adierazten den egunean (1960-5-2) heriotza zigorraren bidez hildako gaizkilea da; baina ez da ahaztu behar askoren iritziz gehiegizko zigorra izan zela eta egotzitako krimenetako bere partaidetza ez zela inoiz guztiz frogatu. Bestalde, Caryl Chessmanek bere bizipenen inguruko hiru liburu eta nobela bat ere argitaratu zituen.

Istorio hau egongo litzateke beraz, titulutzat "Caryl Chessman" duen poemaren atzean; krudelkeria eta heriotza idazketarekin eskutik helduta berriro ere.

Pertsonaia nagusien izen sinbolikoak aztertu ditugun heinean, konturatu gaitezke liburuko pertsonaiek eta erreferentzia intertestualaren eraginez aipatzen diren pertsonaiek badituztela euren artean antzekotasun nabarmenak. Pertsonaia erreal guztiak (Hölderlin, Bilintx, Antonin Artaud, Theo eta Vincent Van Gogh...) euren bizitzaren zati batean bederen, erotasunaren eta bazterketaren magalean kulunkatu ziren eta Ziutateaz liburuan ere euren trataera ildo honek baldintzatuko du.

\section{$\rightarrow$ Intertestualitate inplizitua.}

Lehen esan bezala, intertestualitate inplizitu bezala izendatuko ditugu agerikoak izan gabe oinarrian egon daitezken Ziutateaz-eko ezaugarri intertestualak.

Batetik, lehen aipaturiko liburuan jorratzen den Ankerkeriaren antzerkia berreskuratu behar dugu bestelako oinarri intertestual bat proposatzeko. Honela bada, eta Antonin pertsonaiaren jatorria aztertu badugu ere, Alfred Jarry-z hitz 
egitea zilegi litzateke, eta bereziki bere Ubu Roi (1896) antzerki lan garrantzitsuaz. Antzerki lan honetan Ubu erregeak, marioneta grotesko bezain zikoitzak, biolentziaren eta traizioaren bidez boterea eskuratu beste obsesiorik ez du, edonolako triskantzak aurrera eramanez. Sarritan interpretatu izan den bezala, Uburen oinarrian beti egon izan diren eta beti egongo diren tiranoak edo diktadoreak daude. Agian, beste arrazoien artean, honengatik proposatuko zuen Alfred Jarry-k marioneta bat Ubu pertsonaia gauzatzeko, aurpegia maskara batez estalitako txotxongilo lodi bat hain zuzen.

Antzerki lan honek eta Ziutateaz-ek aurkezten dituzten paralelismoak ez dira gutxi. Uburen argumentuak Ziutateaz-en argumenturako ere balioko luke, Atxagaren liburuan Scardenalli tirano ankerrak boterea eskuratzeko zernahi egingo baitu.

Bestalde, Ubu erregearen irudia dela eta, maskaraz estaliriko marioneta gizenak zentzu erabat metaforikoa duela esan behar da, bere itxurak gaizkiaren anonimatoa, gezurra, iruzurra eta gupida eza estaltzen baititu. Ziutateaz liburuan aldiz, bada Antoninen pasartean mozorroek protagonismoa hartzen duten zati bat: "estalia ibiltzen dut aurpegia, eta ezin dezaket neure maskara kendu, gauean eta gelaren bakardadean ez bada. Hala agintzen digu etxeko jaunak, Scardenallik (...)"(Atxaga, 1986: 59).

Honela, Ankerkeriaren antzerkiarekin batera Alfred Jarry-ren antzerkiaren eragina nabarmendu daiteke Atxagaren liburuan. Bi antzerki moldeek proposatzen dute errealitatea islatu asmo duen antzerkiarekiko eszeptizismoa eta aukera hau baztertu ondoren, antzerkiarentzat planteamendu berriak proposatzen dituzte: irudimenaren antzerkia esaterako.

Eragin gehiago atzematearren, Hyeronimus izenaren jatorria aztertu daiteke, lehen aipatu bezala Caronteren ezaugarriak dituen irudia izen horrekin bataiatzen baitu Atxagak. Izen aldaketa honen jatorriaren irakurketa posible bat aurkeztuko dugu jarraian, arriskatuegia akaso. Van Gogh eta Theoren kasuan erreferentzia piktorikoek zeresana duten neurrian, orain ere pinturaren esparrua landuko dugu. Hyeronimus izena bere horretan hartzen badugu, Hyeronimus Bosch "Bosco" pintorearen izena izan daitekeela esan genezake. "Bosco"ren obren artean ezagunenetakoa berriz, Jardín de las delicias litzateke. Irudi honen interpretazioak zuzenean garamatza ongia eta gaizkiaren arteko betiko gatazkara, paradisua eta infernuaren gai eternalera. Nolabait esateko, Ziutateaz liburuko gai garrantzitsuenetako bat hau litzateke, krudelkeria eta onginahiaren arteko betiko borroka. Ikaroek hegan egin nahi izan arren debekatua dago hegaldatzea eta debeku hori heriotzarainoko jazarpen bilakatuko da.

Berriro arlo piktorikora itzuliz, "Bosco" eta bere teknika zein tematika erabili zituen jarraitzaileen artean berriz Joachim Patinir margolaria aipatu behar da. Hain zuzen, ongia/gaizkia edo paradisua/infernua antitesiak islatzen eta adierazten dituen 
lan bat hartu behar dugu kontutan: Paso de la laguna Estigia. Paradisua eta infernua elkarri aurka eginez koadroaren alde banatan kokatzen ditu Patinirrek, erdian Estigia ibaia kokatzen duelarik. Eta irudiaren erdi-erdian Caronte agertzen da, txalupa baten gainean, itsua dela igarri daiteke eta arima bat daramala infernura.

Ziutateaz-ek asko du irudimenetik, kontrazalean bertan prestatzen gaitu Atxagak etorriko denaz zera dioenean: "Idazterakoan, ikuspuntu naturalista edo zinematografikotik abalik eta gehiena urruntzen saiatu nintzen" baieztatzen duenean; edota Josu Landak bere artikuluan honakoa dioenean; "Scardenalliren historia irakurtzerakoan amets batetan garela inpresioa jasotzen dugu: deskripzioetan konkretotasunak ibesegiten du, pertsonaien jazoerak eta enplegatutako sinboloak dira inportanteena".

\section{ZIUTATEAK ETA HIRIAK}

Aztertu ditugun ardatz tematikoekin eta aztarna intertestualekin ongi baino hobeto islatzen da Ziutateaz liburuan aurkezten den hiriaren irudia. Pertsonaia eroz, ankerrez, bihozgabez betetako hiri honek ezin zuen bestelakoa izan; liburuan agertzen diren gatazka odoltsuak eta ilunak ez daude besterik gabe jarriak; narrazioen estiloa eta kontatzeko modua ere literatur tradizio jakin bati lotzen zaizkio; eta elementu guzti hauek bakar zein berezi den ziutate bat eraikitzen dute.

Ziutate distopiko honetan utopiak ez du lekurik, utopiaren ukapen erabatekoa baitago sustraietan; hiri hau ez da infernu bat ere, infernuak ere baduelako bere lekua. Ziutateaz lanean agertzen den hiria, azken finean, ez baita inon eta aldi berean edonon dagoen hiri hori.

\section{Bibliografia aipatua}

- Artaud, Antonin; [Le théâtre et son double, 1938]; El teatro y su doble, Bartzelona, Edhasa, 1999.

- Atxaga, Bernardo; Ziutateaz, Donostia, Erein, 1986.

— Jarry, Alfred; [Ubu Roi, 1896], Úbu rey, Madrid, Cátedra, 1997.

— Kristeva, Julia, Semiótica I, Espiral, 1978.

— Olaziregi, Mari Jose, Bernardo Atxagaren irakurlea, Donostia, Erein, 1998.

, Euskal Eleberriaren bistoria: Santiago Onaindia ikerketa beka 1999, Bilbo, Labayru ikastegia, 2000.

- Scheurmann, K (editore lanak)., Para Walter Benjamin, Bonn, Inter nationes, 1992.

- Josu Landa; "Ziutateaz eta Etiopia: obsesio berdinez eraikitako bi unibertso", Susa aldizkaria, 5. alea, 1982 apirila. 